\title{
Fuzzy Logic Based Virtual Inertia Control of DFIG Based Wind Generator for Stability Improvement of Hybrid Power System
}

\author{
Md. Rifat Hazari*a) Student Member, \\ S. M. Muyeen *** Non Member, \\ Rion Takahashi* Member,
}

\author{
Mohammad Abdul Mannan** Non Member \\ Atsushi Umemura* \\ Junji Tamura*
}

(Manuscript received Jan. 00, 20XX, revised May 00, 20XX)

\begin{abstract}
Large integration of renewable energy sources (RESs), such as wind power and solar photovoltaic (PV) plants, into the power systems, impacts the system frequency stability. Normally, a wind farm (WF) and PV system do not provide frequency support because of the uncontrollability of the input energy. Moreover, overall system inertia will be reduced due to massive integration of RES because conventional generation units that provide reserve power need to be decreased. To overcome the problems of frequency stability as well as power system transient stability resulting from the insufficient inertia response, this paper proposes a new method to enhance the transient stability of the power system with RESs introduced, in which variable speed wind turbine with doubly fed induction generator (VSWT-DFIG) supplies its kinetic energy (KE) during generation outage to stabilize conventional synchronous generators (SGs). A suitable fuzzy logic based virtual inertia controller (VIC) is proposed to release the stored KE efficiently during transient period. This fuzzy logic controller (FLC) can continuously adjust the VIC gain depending upon the incoming wind speed. To verify the effectiveness of the proposed VIC, simulation analyses are performed on a multimachine hybrid power system model composed of PV plant, VSWT-DFIG, fixed speed wind turbine with squirrel cage induction generator (FSWT-SCIG), and conventional SGs.
\end{abstract}

Keywords: PV plant, DFIG, SCIG, virtual inertia, fuzzy logic controller, and hybrid power system.

\section{Introduction}

Environmental concern and the continuous increase in demand for electricity have demanded finding alternative energy sources and developing methods to utilize existing RESs more efficiently. Among the existing RESs, wind power generation is increasing very quickly worldwide with a prediction of over $800 \mathrm{GW}$ power rating by the end of $2021^{(1)}$. On the other hand, solar PV station is also considered as a popular RES. The solar energy will reach the significant place among the RESs within 2040 and satisfying nearly $28 \%$ of all the overall energy demand across the world ${ }^{(2)}$. Though integration of large scale RESs, for example wind power and PV power plants, into the power system decreases the dependence on fossil fuel, the total system inertia will be reduced because of gradual replacement of the conventional SGs. Therefore, the high penetration of RESs into the power system can lead to critical frequency stability challenges ${ }^{(3)}$, because the RESs typically have low or no inertial responses ${ }^{(4)}$. For example, solar PV plants do not provide any inertia response to the power system as it has no

a) Correspondence to: Md. Rifat Hazari. E-mail: rifat.hazari@gma il.com

* Department of Electrical and Electronic Engineering, Kitami Institute of Technology (KIT), 165 Koen-cho, Kitami, Hokkaido 090-8507, Japan

** Department of Electrical and Electronic Engineering, American International University-Bangladesh (AIUB), 408/1, Kuratoli, Khilkhet, Dhaka 1229, Bangladesh

*** Department of Electrical and Computer Engineering, Curtin University, Perth, WA, Australia rotational masses ${ }^{(4)}$. Furthermore, VSWTs are connected to the grid through full or partial power electronic converter, which usually decouples the wind turbine inertia from the power system and thus they also cannot provide inertial response during transient period.

To solve the difficulties of frequency stability as well as power system transient stability resulting from small inertia of the power system, RESs are expected to create new virtual inertia to support the power system during transient period, such as VSWT-DFIG with VIC.

In literatures ${ }^{(5)-(13)}$, virtual inertia control strategy of VSWTs is designed in order that the VSWTs can supply the KE stored in their rotor to improve the frequency dip. To enable VIC, these arrangements employ supplementary circles based on the measured system frequency, for example, rate of change of frequency (ROCOF) circle ${ }^{(5)-(7)}$, droop circle ${ }^{(8)}$, and ROCOF and droop circles (9)-(13). The above-mentioned schemes can arrest the frequency dip by releasing the KE stored in its rotor. But, the control gains are constant for a specific system composition and wind speed for the above arrangements. Therefore, difficulty rises in finding a specific constant gain of VSWT which is suitable for various wind speed conditions. In addition, the control gain should be changed according to the system composition to store/release significant amount of KE during transient period.

To overcome the above-mentioned issues, this paper proposes a new FLC based VIC for DFIG. The proposed FLC can provide variable control gain depending upon the incoming wind speed and thus it is independent of the system composition. The proposed controller is very effective to supply KE during transient condition 


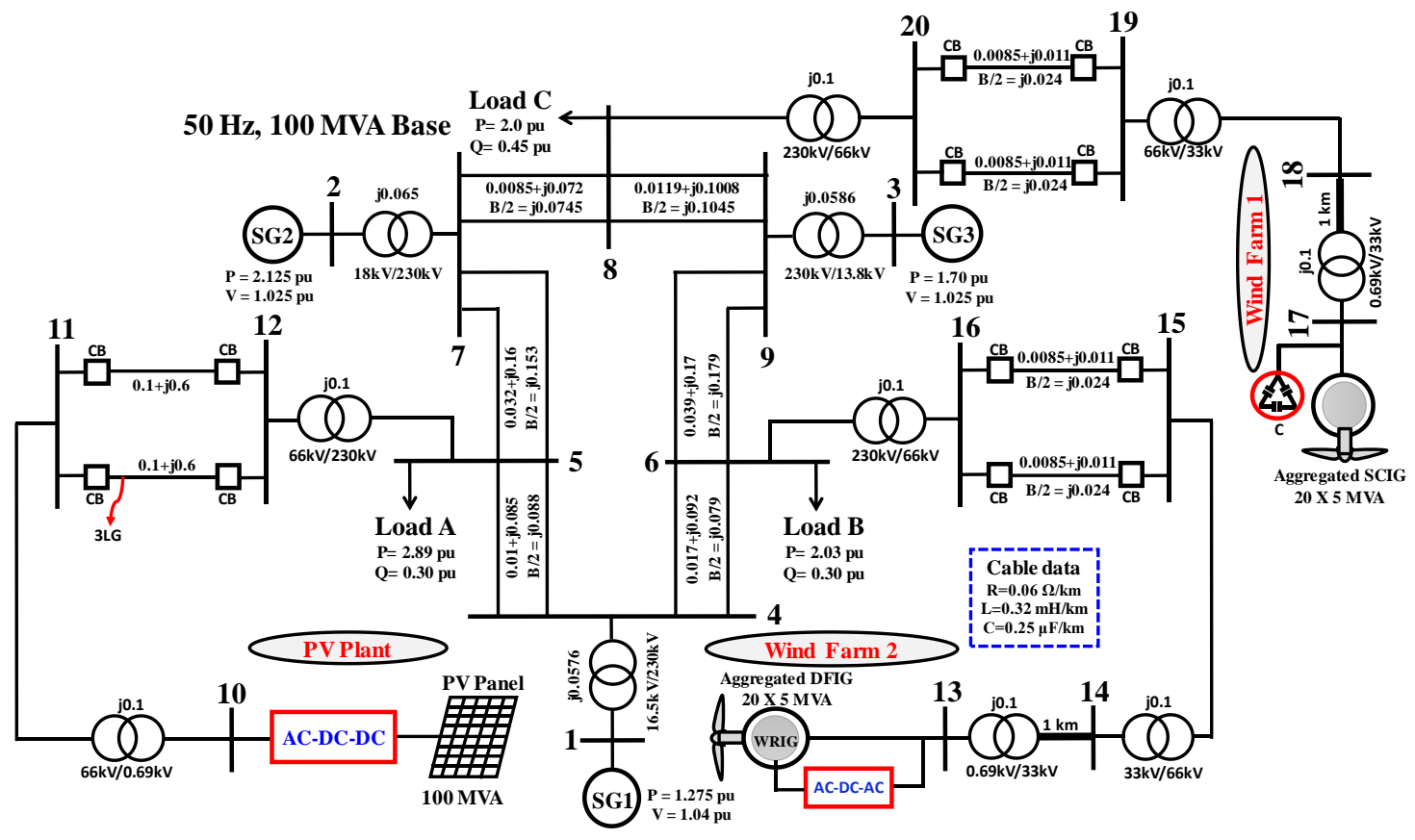

Fig. 1. Hybrid power system model.

in the form of inertial response. The transient performance of the overall system composed of PV plant, VSWT-DFIG with proposed VIC, FSWT-SCIG, and conventional SGs is analyzed and compared with that composed of a DFIG without VIC. Finally, it is shown that the stability of conventional SGs as well as total power system can be enhanced by using the proposed VIC.

\section{Description of the Hybrid System Model}

The hybrid power system model shown in Fig. 1 is composed of a multi-machine main system, two WF, and a solar PV station. The WF 1 is connected to the main system at bus 8 through transformers and double circuit transmission line. The WF 1 is an aggregated model of 20 FSWT-SCIGs and each unit has the power rating of 5 MVA. The total capacity of WF 1 is 100 MVA. The capacitor bank (C) is used to compensate reactive power demand of the SCIG. The value of $\mathrm{C}$ is chosen so that the power factor $(\mathrm{PF})$ of the SCIG becomes unity at the rated operating condition. The WF 2 is connected to the main system at bus 6 through transformers and double circuit transmission line. The WF 2 is also an aggregated model of 20 VSWT-DFIGs and each unit has the power rating of 5 MVA. The total capacity of WF 2 is also 100 MVA. In the simulation analyses, an individual wind turbine is scaled up to model the 100 MVA for both WF 1 and WF 2 to reduce the computation time ${ }^{(14)-(15)}$. The parameters of DFIG and SCIG are presented in Table 1.

Also, a solar PV station is connected to the main system at bus 5 as shown in Fig. 1. The capacity of the PV plant is 100 MVA. The detailed design procedure of PV power plant will be discussed in appendix.

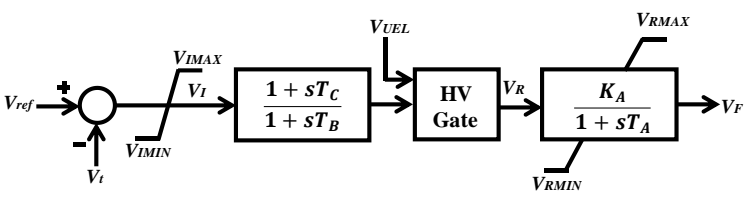

Fig. 2. IEEE type AC4A excitation system model.
The main system is composed of three conventional power plants: two thermal power plants (SG1 and SG2) and one hydro power plant (SG3). Both SG1 and SG3 are operated under automatic generation control (AGC), and SG2 is operated under governor free (GF) control. The parameters of the SGs are listed in Table 2.

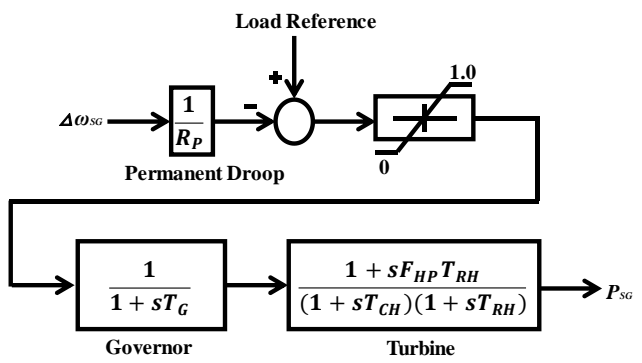

Fig. 3. Steam turbine governor model.

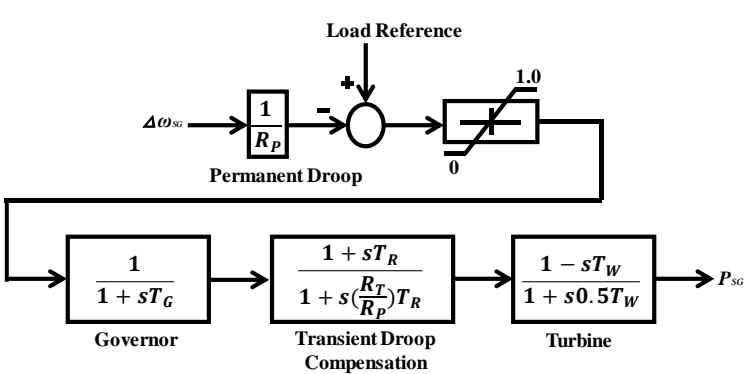

Fig. 4. Hydro turbine governor model.

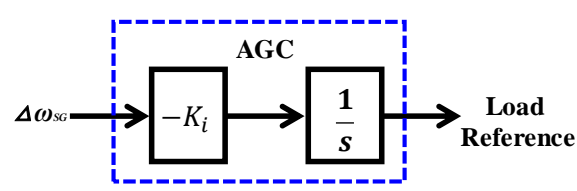

Fig. 5. Controller for AGC. 
Table 1. Parameters of DFIG and SCIG.

\begin{tabular}{|c|c|c|c|}
\hline \multicolumn{2}{|c|}{ DFIG } & \multicolumn{2}{c|}{ SCIG } \\
\hline MVA & 5 & MVA & 5 \\
\hline$R_{s}$ & $0.007 \mathrm{pu}$ & $R_{I}$ & $0.01 \mathrm{pu}$ \\
\hline$R_{r}$ & $0.005 \mathrm{pu}$ & $X_{I}$ & $0.1 \mathrm{pu}$ \\
\hline$L_{i s}$ & $0.171 \mathrm{pu}$ & $X_{m}$ & $3.5 \mathrm{pu}$ \\
\hline$L_{r l}$ & $0.156 \mathrm{pu}$ & $R_{21}$ & $0.035 \mathrm{pu}$ \\
\hline$L_{m}$ & $2.9 \mathrm{pu}$ & $R_{22}$ & $0.014 \mathrm{pu}$ \\
\hline$H$ & $1.5 \mathrm{~s}$ & $X_{21}$ & $0.03 \mathrm{pu}$ \\
\hline$H_{t}$ & $4.42 \mathrm{~s}$ & $X_{22}$ & $0.089 \mathrm{pu}$ \\
\hline$D$ & 1.5 & $H$ & $1.5 \mathrm{~s}$ \\
\hline$K$ & 296 & & \\
\hline
\end{tabular}

Table 2. Parameters of synchronous generators.

\begin{tabular}{|c|c|c|c|}
\hline Parameter & SG1 & SG2 & SG3 \\
\hline Rated Power & $150 \mathrm{MVA}$ & $250 \mathrm{MVA}$ & $200 \mathrm{MVA}$ \\
\hline Voltage & $16.5 \mathrm{kV}$ & $18 \mathrm{kV}$ & $13.8 \mathrm{kV}$ \\
\hline$R_{a}$ & $0.003 \mathrm{pu}$ & $0.003 \mathrm{pu}$ & $0.003 \mathrm{pu}$ \\
\hline$X_{l}$ & $0.1 \mathrm{pu}$ & $0.1 \mathrm{pu}$ & $0.1 \mathrm{pu}$ \\
\hline$X_{d}$ & $2.11 \mathrm{pu}$ & $2.11 \mathrm{pu}$ & $1.20 \mathrm{pu}$ \\
\hline$X_{q}$ & $2.05 \mathrm{pu}$ & $2.05 \mathrm{pu}$ & $0.700 \mathrm{pu}$ \\
\hline$X^{\prime}{ }_{d}$ & $0.25 \mathrm{pu}$ & $0.25 \mathrm{pu}$ & $0.24 \mathrm{pu}$ \\
\hline$X^{\prime \prime}{ }_{d}$ & $0.21 \mathrm{pu}$ & $0.21 \mathrm{pu}$ & $0.20 \mathrm{pu}$ \\
\hline$X^{\prime \prime}{ }_{q}$ & $0.21 \mathrm{pu}$ & $0.21 \mathrm{pu}$ & $0.20 \mathrm{pu}$ \\
\hline$T_{d o}$ & $6.8 \mathrm{~s}$ & $7.4 \mathrm{~s}$ & $7.2 \mathrm{~s}$ \\
\hline$T^{\prime \prime}{ }_{d o}$ & $0.033 \mathrm{~s}$ & $0.033 \mathrm{~s}$ & $0.031 \mathrm{~s}$ \\
\hline$T^{\prime \prime}{ }_{q o}$ & $0.030 \mathrm{~s}$ & $0.030 \mathrm{~s}$ & $0.030 \mathrm{~s}$ \\
\hline$H$ & $4.0 \mathrm{~s}$ & $4.0 \mathrm{~s}$ & $4.0 \mathrm{~s}$ \\
\hline
\end{tabular}

Table 3. Typical values of IEEE type AC4A excitation system.

\begin{tabular}{|c|c|}
\hline Parameter & Value \\
\hline$K_{A}$ & 200 \\
\hline$T_{A}$ & 0.04 \\
\hline$T_{B}$ & 12 \\
\hline$T_{C}$ & 1.0 \\
\hline
\end{tabular}

Table 4. Typical values of turbine parameters.

\begin{tabular}{|c|c|c|c|}
\hline \multicolumn{2}{|c|}{ Steam Turbine } & \multicolumn{2}{c|}{ Hydraulic Turbine } \\
\hline Parameter & Value & Parameter & Value \\
\hline$R_{p}$ & 0.05 & $R_{p}$ & 0.05 \\
\hline$T_{G}$ & $0.2 \mathrm{~s}$ & $T_{G}$ & $0.2 \mathrm{~s}$ \\
\hline$T_{C H}$ & $0.3 \mathrm{~s}$ & $R_{T}$ & $0.38 \mathrm{~s}$ \\
\hline$T_{R H}$ & $7.0 \mathrm{~s}$ & $T_{R}$ & $5.0 \mathrm{~s}$ \\
\hline$F_{H P}$ & 0.3 & $T_{W}$ & $1.0 \mathrm{~s}$ \\
\hline
\end{tabular}

The IEEE type AC4A excitation system model shown in Fig. 2 is considered for all SGs. Table 3 lists the parameters of AC4A exciter. In this study, the standard models are used as the turbine and governor models of thermal and hydro units. Fig. 3 shows a block diagram of the reheat steam turbine governor system used in the thermal power plants (SG1 and SG2). The hydro turbine governor model used for the hydropower plant (SG3) is shown in Fig. 4. The parameters of both turbine systems are presented in Table 4. For AGC operation, an integral controller is used on the governor system for both SG1 and SG3. The integral gain $\left(K_{i}\right)$ is set to 6 . The
MVA base of the power system is 100 MVA, and the rated frequency is $50 \mathrm{~Hz}$.

\section{Modeling of Wind Farm}

\subsection{Aerodynamic Modeling of Wind Turbine}

The wind power is received by the wind turbine and the converted mechanical power can be expressed as follows ${ }^{(16)}$ :

$$
\begin{aligned}
& P_{w}=0.5 \rho \pi R^{2} V_{w}^{3} C_{p}(\lambda, \beta) \\
& C_{p}(\lambda, \beta)=c_{1}\left(\frac{c_{2}}{\lambda_{i}}-c_{3} \beta-c_{4}\right) e^{\frac{-c_{5}}{\lambda_{i}}}+c_{6} \lambda \\
& \frac{1}{\lambda_{i}}=\frac{1}{\lambda-0.08 \beta}-\frac{0.035}{\beta^{3}+1} \\
& \lambda=\frac{\omega_{r} R}{V_{w}}
\end{aligned}
$$

From Eq. (1), the captured mechanical power output of wind turbine $\left(P_{w}\right)$ is calculated based on the air density $(\rho)$, radius of the blade $(R)$, incoming wind speed $\left(V_{w}\right)$, and power coefficient $\left(C_{p}\right)$. Where, $C_{p}$ is the function of tip speed ratio $(\lambda)$ and blade pitch angle $(\beta)$. The $C_{p}$ is determined depending on $\lambda$ and $\beta$ as expressed in Eqs. (2) and (3). Here, $c_{l}$ through $c_{6}$ are the characteristic coefficients of the wind turbine $\left(c_{1}=0.5176, c_{2}=116, c_{3}=0.4, c_{4}=5, c_{5}=21\right.$, and $\left.c_{6}=0.0068\right)^{(17)}$. The $\lambda$ is calculated from Eq. (4) by using $R, V_{w}$, and rotational speed of the wind turbine $\left(\omega_{r}\right)$.

The $C_{p}-\lambda$ characteristics shown in Fig. 6 are obtained using Eq. (2) with different values of $\beta$. When $\beta$ is equal to zero degree, the optimum power coefficient $\left(C_{\text {popt }}\right)$ is 0.48 , and the optimum tip speed ratio $\left(\lambda_{o p t}\right)$ is 8.1 .

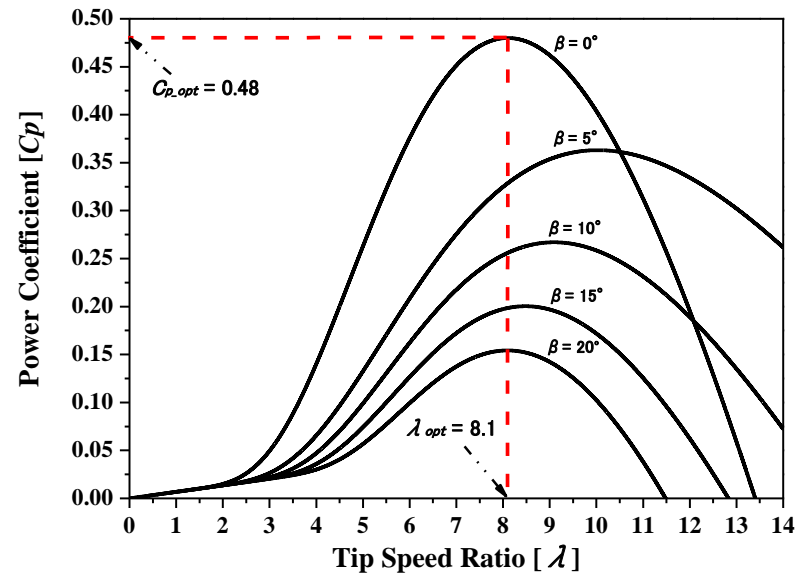

Fig. 6. $\quad C p-\lambda$ characteristics of the wind turbine for various pitch angles.

Fig. 7 shows the maximum power point tracking (MPPT) curve for the VSWT-DFIG ${ }^{(18)}$. The MPPT curve is divided into four operating regions depending on the available wind speed as follows (18):

(a) Minimum speed region (point A to point B): In this region, the DFIG speed is about $70 \%$ of the synchronous speed.

(b) Optimum speed region (point B to point C): This operating point is the most efficient operation of DFIG until it reaches to the maximum speed (which is about $120 \%$ of the synchronous speed).

(c) Maximum speed region (point $\mathrm{C}$ to point $\mathrm{D}$ ): At this operating point, the generator speed reaches its maximum speed and rotor side 
converter (RSC) of DFIG works to keep the DFIG speed at maximum speed.

(d) Limited speed region: At this operating point, the mechanical power production can exceed the rated power due to the increases of incoming wind speed. Thus, the pitch controller is activated to maintain turbine speed.

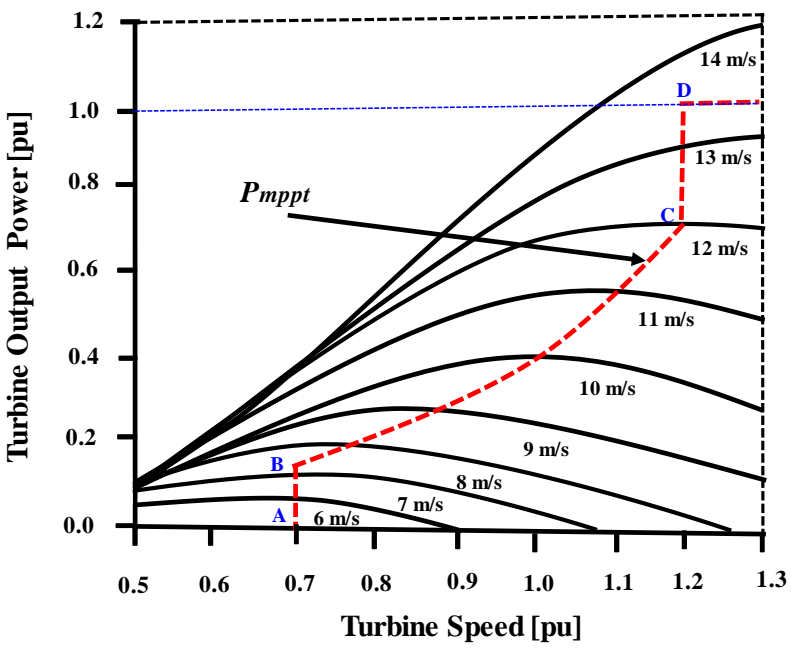

Fig. 7. Wind turbine characteristics for the DFIG under MPPT.

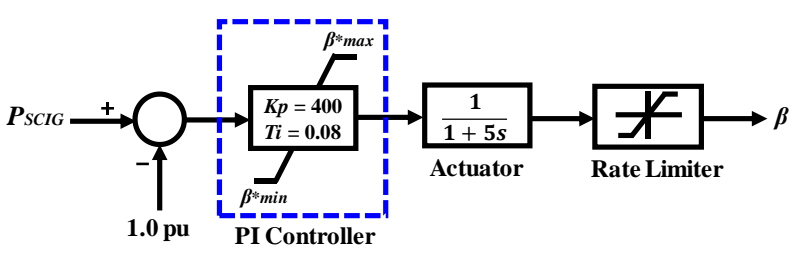

Fig. 8. Pitch controller for FSWT.

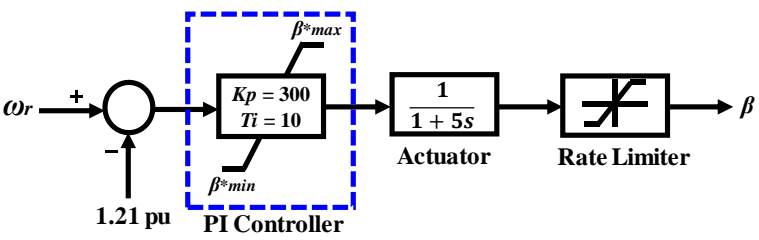

Fig. 9. Pitch controller for VSWT.

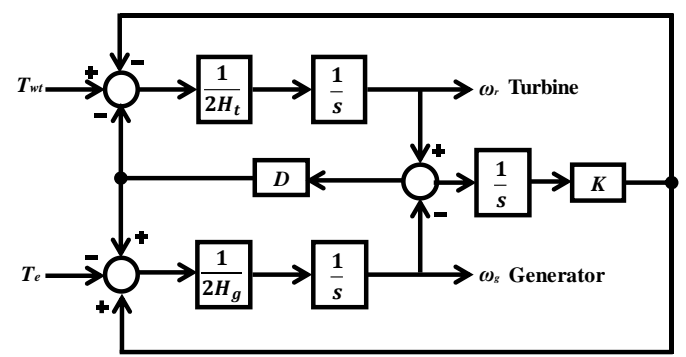

Fig. 10. Two-mass drive train model.

Figs. 8 and 9 show the models of the blade pitch control system for FSWT and VSWT ${ }^{(19)}$, respectively. In FSWT, the pitch control system is used to control the power output of the SCIG so as not to exceed the rated power. In VSWT, the pitch controller is used to regulate the rotational speed of the DFIG so as not to exceed the rated speed. A proportional-integral (PI) controller is used to compensate the error signal.
Fig. 10 represents the two-mass drive train model which is considered in this work ${ }^{(18),(20)}$, where $H_{t}, H_{g}, D$ and $K$ are the turbine inertia constant, generator inertia constant, damping of turbine and spring constant, respectively.

3.2 Modeling of DFIG Fig. 11 shows the typical configuration of VSWT-DFIG along with its control system used in this work, which consists of wind turbine model with aerodynamic characteristics, a pitch controller, a wound rotor induction generator (WRIG), and an AC/DC/AC converter based on two levels of insulated gate bipolar transistors (IGBTs). The AC/DC/AC converter is controlled by the RSC controller and the grid side converter (GSC) controller, respectively.

The wind turbine drives the WRIG to convert wind power into electrical power. The rotational speed $\left(\omega_{r}\right)$ is obtained from the rotor of the WRIG. The WRIG model available in the PSCAD library is used in the present study ${ }^{(21)}$. The rotor position $\left(\theta_{r}\right)$ is derived from the rotor of the WRIG. As shown in Fig. 11, the stator terminal is directly connected to the grid. The RSC and GSC is installed between the rotor of the WRIG and the grid. The power rating of the converter is $30 \%$ of the WRIG rating.

The pulse width modulation (PWM) technique is used to generate the necessary gate pulses for driving the RSC and GSC. The carrier frequency is taken as $3.0 \mathrm{kHz}$. The RSC is connected to the rotor winding of the WRIG. Based on the wind speed condition, it offers variable frequency excitation to the rotor winding. The GSC is connected to the grid through a transformer.

A protection system with a DC chopper is installed in the DClink circuit. The DC chopper is controlled by the comparator block, which triggers the DC chopper switch when the DC-link voltage $\left(V_{d c}\right)$ becomes greater than or equal to the predefined limit $\left(V_{d c} \geq\right.$ $1.15 \mathrm{pu})$.

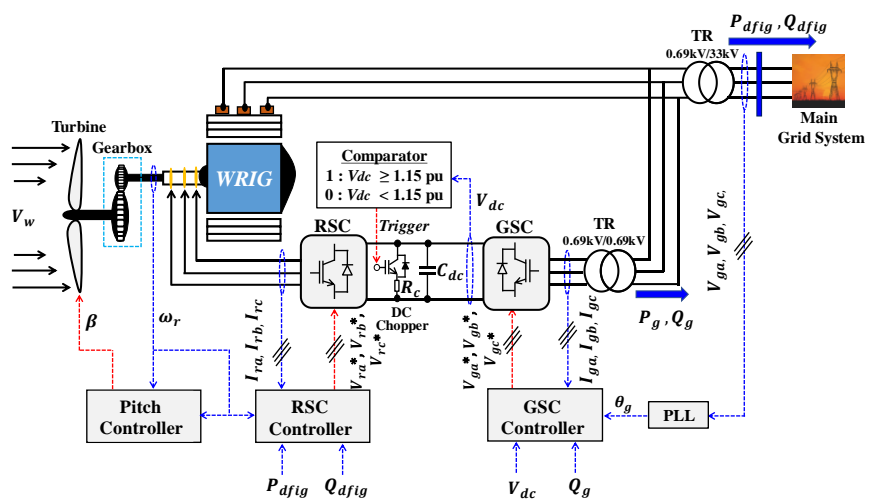

Fig. 11. Typical configuration of VSWT-DFIG.

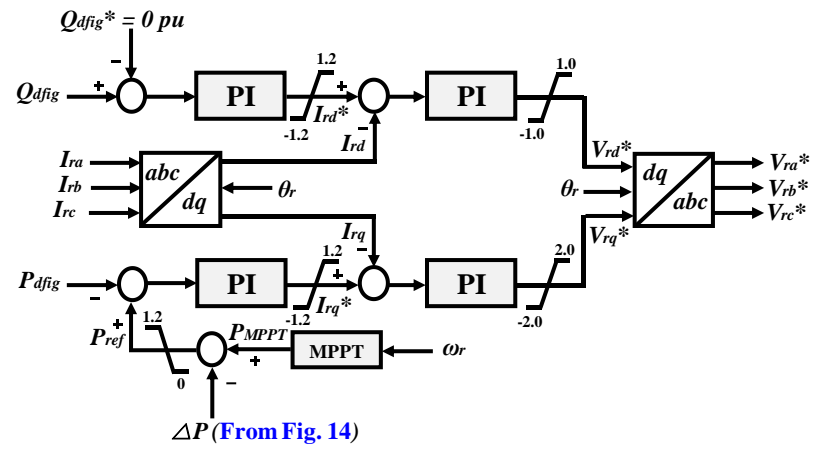

Fig. 12. RSC controller of DFIG. 


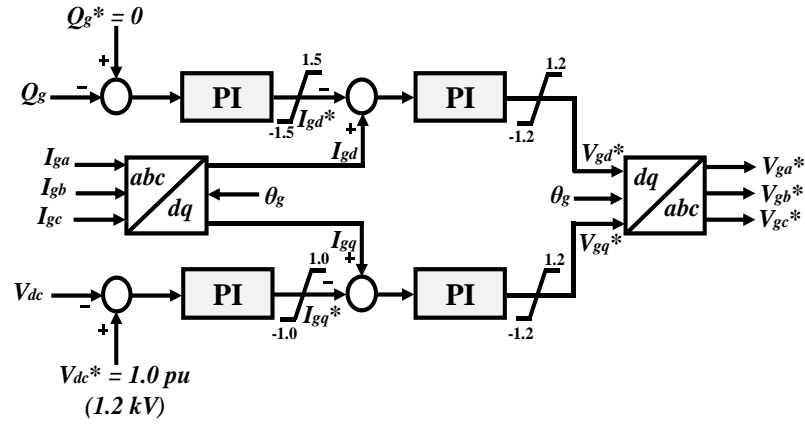

Fig. 13. GSC controller of DFIG.

3.3 Controller of RSC The RSC controller has the main objective to control the active power $\left(P_{d f i g}\right)$ and reactive power $\left(Q_{d f i g}\right)$ injected to the grid system, which is composed of two cascaded controllers as shown in Fig. 12. The outer loops regulate the decoupled $P_{d f i g}$ and $Q_{d f i g}$, whereas the inner current loops regulate the rotor d-axis current $\left(I_{r d}\right)$ and q-axis current $\left(I_{r q}\right)$. The PI controllers are used to track the different error signals. The reference reactive power $\left(Q_{d f i g}{ }^{*}\right)$ is set to zero for unity PF operation. The calculation of reference active power $\left(P_{r e f}\right)$ is very important as it should be corresponding to the maximum amount of active power for a specific wind speed and also it can contribute to the power system during frequency variation event by incorporating some additional control strategy. Therefore, $P_{\text {ref }}$ is determined to be the sum of the MPPT power $\left(P_{M P P T}\right)$, which derived from the Fig. 7, and KE output $(\triangle P)$ in the proposed strategy. The detail calculation of $\Delta P$ will be discussed in the Section 4 .

3.4 Controller of GSC The GSC has a control duty to keep the $V_{d c}$ at a constant level regardless of the rotor power flow and reactive power exchange between the gird side and GSC. Similar to the RSC controller, GSC controller also has the two cascaded controllers as shown in Fig. $13^{(18)}$. The inner loops are responsible for controlling the grid side d-axis current $\left(I_{g d}\right)$ and qaxis current $\left(I_{g q}\right)$, while the outer loops are controlling the $V_{d c}$ and reactive power of the grid $\left(Q_{g}\right)$. The grid side reactive power reference $\left(Q_{g}{ }^{*}\right)$ is set to zero for unity PF operation.

\section{Proposed Virtual Inertia Controller}

The mechanical power of conventional SG does not change for short duration of time during the frequency variation events, because the governor system cannot act quickly. Therefore, the electric power is supplied from the KE by varying its rotor speed to damp the frequency fluctuations.

The quantity of hidden inertia in the rotor of DFIG is significant when its changeable rotor speed range is between $0.7-1.3 \mathrm{pu}^{(22)}$.

To make it possible for the DFIG to regulate the active power during frequency variation, a VIC shown in Fig. 14 is proposed in this work. The proposed VIC mimics the inertial response behavior of a directly-coupled SGs (23), (24).

From Fig. 14, the expression of $\Delta P$ can be written as:

$$
\triangle P=-K_{b} d f_{s y s} / d t
$$

Where, $K_{b}=$ variable gain. This $\Delta P$ will be input to the RSC controller of Fig. 12.

The rate of change of system frequency $\left(d f_{\text {sys }} / d t\right)$ is considered as input variable. When there is any sudden frequency variation, the active power compensation needs to be supplied to the grid. This additional power $(\triangle P)$ will come from the stored $\mathrm{KE}$ of the wind turbine rotor. The performance of the VIC is affected by the value of the control gain $\left(K_{b}\right)$.

Usually, $K_{b}$ is considered as twice of the total inertia constant $(H)$ of VSWT system, that is, $K_{b}=2 H^{(25),(26)}$. But $K_{b}$ is not equal to $2 H$ in the present case because of the decoupling of mechanical and electrical frequency in VSWT-DFIG system and MPPT output is calculated based on the rotor speed. Also, the rotor speed of VSWTDFIG depends on wind speed and stored KE in its rotor is different when the wind speed is varied.

Thus, the deceleration of the rotor to supply the additional power will move the wind turbine operation from MPPT when the power system frequency drops. To compensate this operating point shift, $K_{b}$ should be set to a suitable value. When the rotor speed is high, then $\mathrm{KE}$ stored is large, so, $K_{b}$ should be set to high value. Considering this fact, $K_{b}$ should not be constant. To make it variable, a FLC is introduced. The purpose of using the FLC here is to ensure variable gain depending upon the incoming wind speed $\left(V_{w}\right)$. When the input wind speed is low, the FLC provide low gain and during high wind speed this controller provide high gain. The output of the FLC is multiplied by a fixed gain $(G)$ to obtain the desired $K_{b}$. The design of FLC will be discussed in the Section 5.

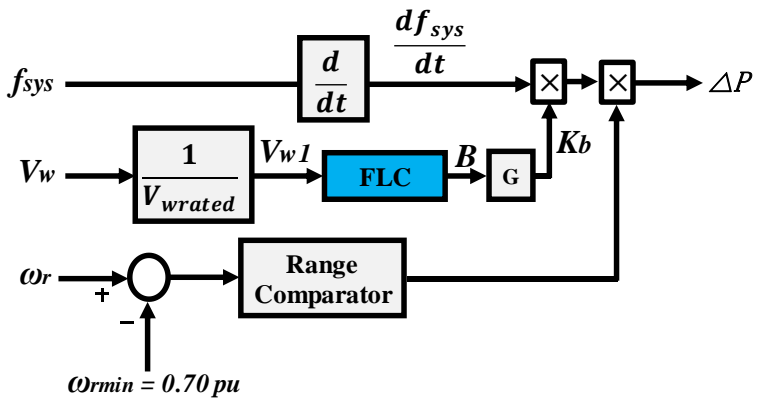

Fig. 14. Proposed virtual inertia controller.

When the KE of DFIG is supplied to the grid to damp frequency variation, the rotor speed of the DFIG is reduced. If the huge amount of KE is extracted, then DFIG can be unstable resulting in large rotor speed decrease. To eliminate the large deceleration of rotor speed, the VIC is only activated when rotor speed exceeds $0.70 \mathrm{pu}$. When the rotor speed is dropped below the minimum rotor speed $\left(\omega_{\text {rmin }}\right)$, the output signal of the comparator between actual rotor speed and $\omega_{\text {rmin }}$ is zero. This is done by using range comparator as shown in Fig. 14. Thus, the product of $d f_{s y s} / d t$ and $K_{b}$ is zero. In this way by using the proposed VIC, the active power output of the VSWT-DFIG is temporarily increased and an inertial response from the wind turbine is achieved.

\section{Fuzzy Logic Controller Design}

The overall structure of FLC is shown in Fig. 15. The FLC is described in the following:

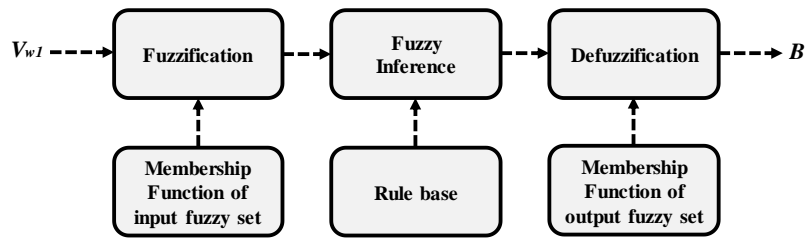

Fig. 15. General structure of FLC. 


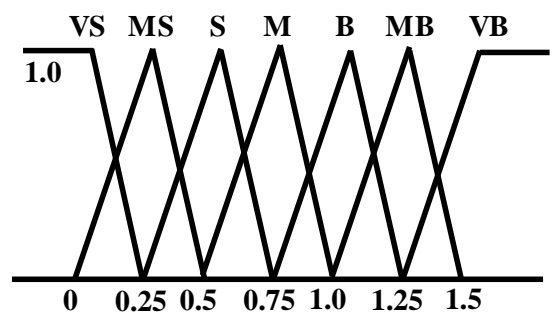

(a) Input $\left(V_{w l}\right)$

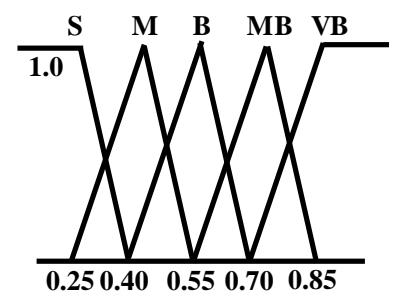

(b) Output (B)

Fig. 16. Membership functions.

Table 5. FLC rules.

\begin{tabular}{|c|c|}
\hline Input $\left(\boldsymbol{V}_{\boldsymbol{w} \boldsymbol{l}}\right)$ & Output (B) \\
\hline VS & $\mathrm{S}$ \\
\hline MS & M \\
\hline S & B \\
\hline M & MB \\
\hline B & MB \\
\hline MB & VB \\
\hline VB & VB \\
\hline
\end{tabular}

5.1 Fuzzification The per unit (pu) wind speed $\left(V_{w l}\right)$ and $B$ in Fig. 15, are chosen as the input and the output, respectively, in the design of the FLC. The triangular membership functions with overlap are used for $V_{w l}$ and $B$ as shown in Fig. 16, in which the linguistic variables VS, MS, S, M, B, MB, and VB stand for Very Small, Medium Small, Small, Medium, Big, Medium Big and Very Big, respectively. The grade of the membership functions is obtained by using the below equation ${ }^{(27)}$ :

$$
\mu(x)=[w-2(x-m)] / 2
$$

Where, $\mu(x), w, m$ and $x$ define the value of grade of membership, the width, the coordinate of the point at which the grade of membership is 1 , and the value of the input variable, respectively.

In the input portion $\left(V_{w l}\right)$, seven grades in the membership function are considered whereas five grades in the output $(B)$ membership functions are chosen. Higher number of grades are considered in the input portion than the output because the wind speed is changing continuously. The parameters of the membership functions are determined by trial and error method to obtain the desired response.

5.2 Rule Base The simplest structure having only one input variable and one output variable is designed in this work, which is the specific features of this FLC. Thus, the use of the single input and output make the FLC very straightforward. The rules are determined based on the working knowledge of the system as depicted in Table 5. The rules of fuzzy mapping of the input variables to the output are represented by IF, THEN condition.
5.3 Fuzzy Inference In this study, the constant value membership functions (Sugeno type) are used for the inference mechanism ${ }^{(28)}$.

5.4 Defuzzification The center of gravity method is used in this study for defuzzification. The output function is given as follows ${ }^{(29)}$ :

$$
B=\frac{\sum_{i=1}^{N} \mu_{i} C_{i}}{\sum_{i=1}^{N} \mu_{i}}
$$

Where, $N$ is the total number of rules, $\mu_{i}$ is the membership grade for $i^{\text {th }}$ rule and $C_{i}$ is the coordinate corresponding to the maximum value of the respective consequent membership function $\left[C_{i} \in\{0.25\right.$, $0.40,0.550 .70,0.85\}$ ] for FLC.

\section{Simulation Analysis and Discussions}

6.1 Simulation Scenarios In this study, simulation analysis has been carried out on the hybrid power system model illustrated in Fig. 1 by using the PSCAD/EMTDC software, where a time step of $10 \mu$ s is considered because of the use of detailed switching model in VSWT-DFIG and PV power plant. The FORTRAN language is incorporated into PSCAD/EMTDC in order to implement FLC as new component. The triple-line-to-ground (3LG) fault near bus 11 is considered as a network disturbance, as shown in Fig. 1. The fault occurs at $0.1 \mathrm{~s}$. The duration of the fault is $0.1 \mathrm{~s}$. The circuit breakers (CBs) on the faulted line are opened at $0.2 \mathrm{~s}$ in order to isolate the faulty line from the power system. The CBs are reclosed at $1.0 \mathrm{~s}$ based on the consideration that the fault has been cleared. The solar irradiance and cell temperature of PV module are kept constant at $1000 \mathrm{~W} / \mathrm{m}^{2}$ and $25^{\circ} \mathrm{C}$ based on the assumption that the irradiance and cell temperature do not change within this short period. Also, the wind speed applied to FSWTSCIG is maintained constant at the rated speed based on the assumption that the wind speed does not change dramatically within this short period. In addition, it is assumed that FSWT-SCIG and PV plant have no low voltage ride-through (LVRT) capability, and thus they are disconnected from the power grid when their terminal voltage is dropped below $70 \%$. In this study, the FSWT-SCIG and $\mathrm{PV}$ plant are disconnected from the grid system at $\mathrm{t}=0.2 \mathrm{~s}$ according to this condition.

Simulation analyses are carried out for two cases to validate the effectiveness of the proposed VIC. In Case A, simulation analysis is performed without any VIC, and in Case B, simulation analysis is performed by considering the proposed VIC.

6.2 Simulation Results for Rated Wind Speed Condition Applied to DFIG This section analyzes the power system dynamic performances when the wind speed applied to DFIG is at rated condition $(12.5 \mathrm{~m} / \mathrm{s})$. According to the condition of Section 6.1, the FSWT-SCIG and PV plant are disconnected from the power system at $\mathrm{t}=0.2 \mathrm{~s}$, thus the active power outputs become zero for both FSWT-SCIG based WF and PV power plant. Due to this shortage of the active power generation, the frequency of the hybrid power system is decreasing in case A, as shown in Fig. 17. Because the VSWT-DFIG system is not equipped with VIC in Case A, it does not generate any additional active power during frequency declining event as shown in Fig. 18. Owing to this weakness of the 
grid, the conventional SGs are supplying excess amount of KE to compensate sudden generation outage as depicted in Fig. 19. As the output of the conventional SGs is not sufficient for compensating the power shortage in Case A, their rotor speeds are decreasing and finally become unstable as depicted in Fig. 20. So, the whole power system becomes unstable in Case A.

On the other hand, the VSWT-DFIG is supporting the power system in Case B after the trip of FSWT-SCIG based WF and PV station by releasing the stored $\mathrm{KE}$ in its rotor for a short period as depicted in Fig. 18. In this case, the power system frequency and rotor speeds of SGs can be going back to the pre-fault values and the whole power system can become stable as shown in Figs. 17 and 20. The rotor speed response of the DFIG is shown in Fig. 21, from which it is seen the rotor speed deviation is larger in Case B than Case A in the transient period. This is because the DFIG is releasing/absorbing power from/into the stored $\mathrm{KE}$ in Case $\mathrm{B}$.

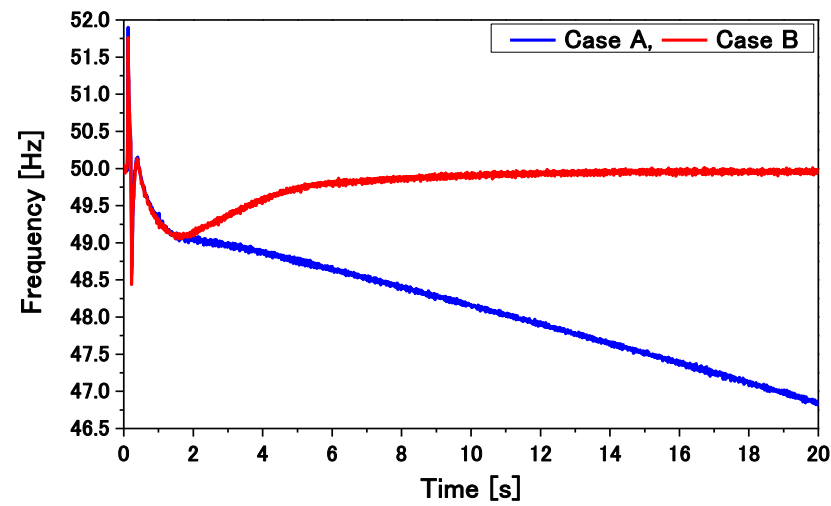

Fig. 17. Frequency response of the hybrid power system.

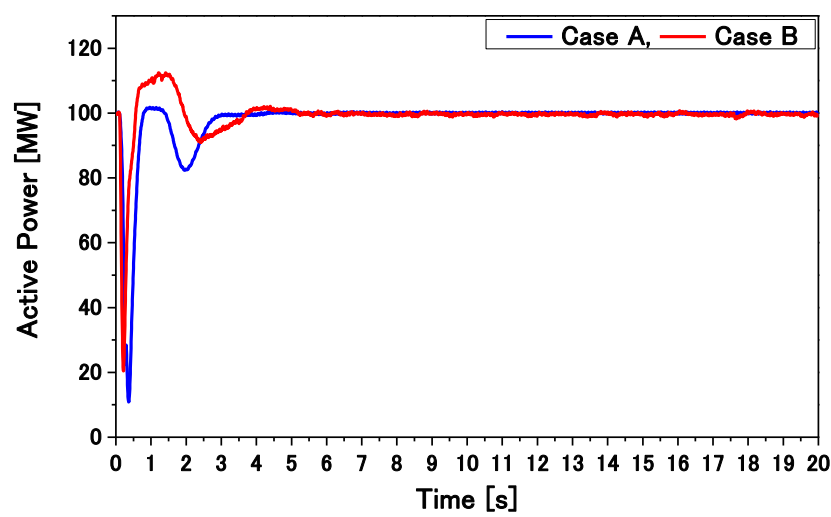

Fig. 18. Active power output of VSWT-DFIG.

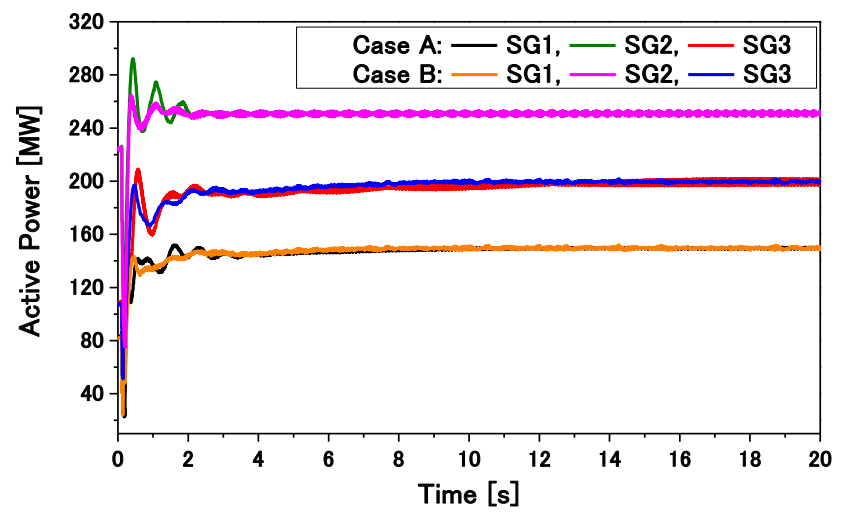

Fig. 19. Active power output of conventional SGs.

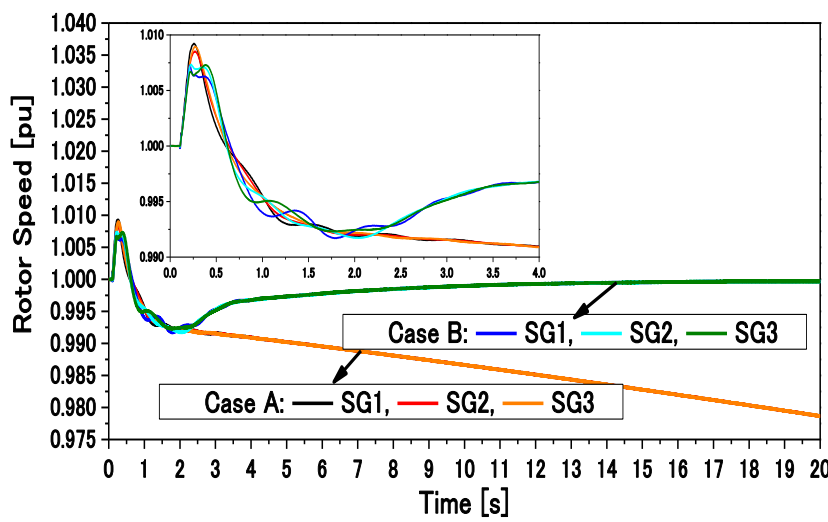

Fig. 20. Rotor speed response of conventional SGs.

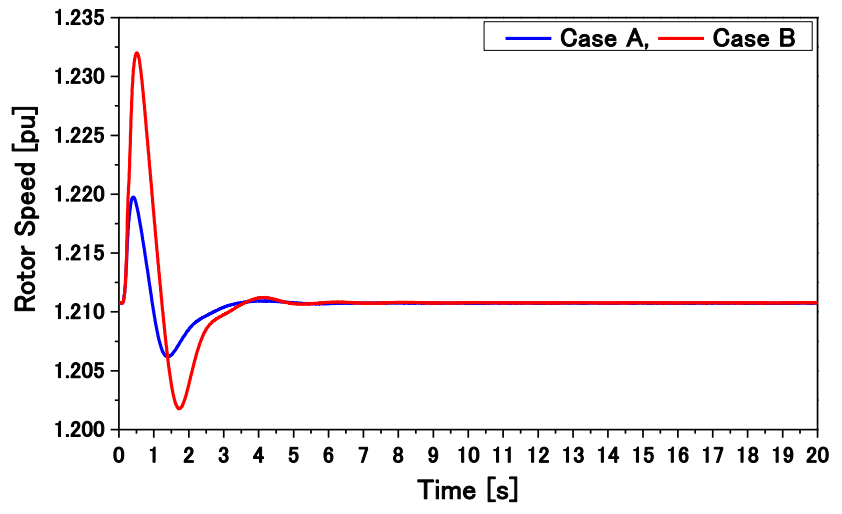

Fig. 21. Rotor speed response of VSWT-DFIG.

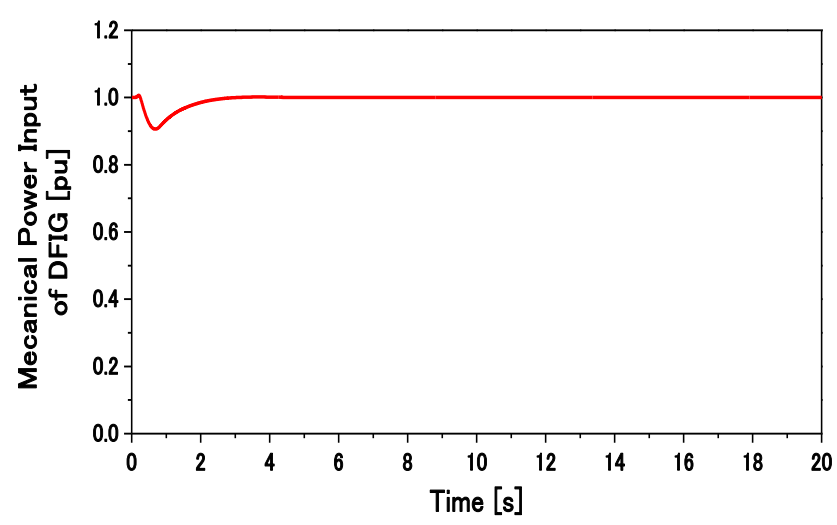

Fig. 22. Mechanical power input of DFIG (Case B).

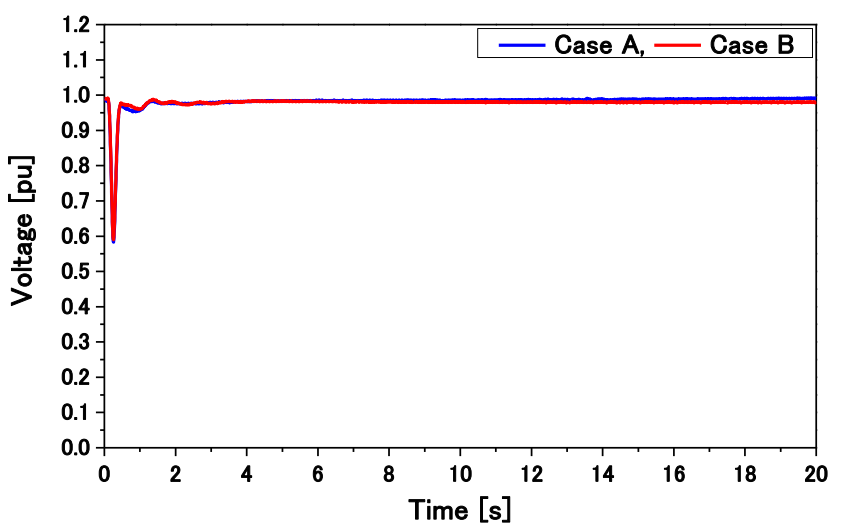

Fig. 23. Terminal voltage response of VSWT-DFIG based WF. 


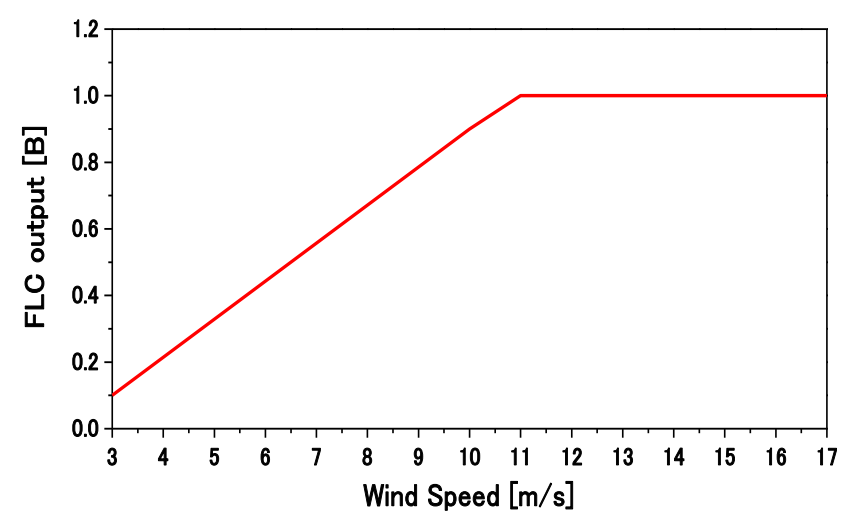

Fig. 24. FLC output (Case B).

Fig. 22 illustrates the mechanical power input of DFIG in Case B. When the rotor speed decreases, the turbine output power also decreases. As a result, the DFIG is no longer operates at MPPT operation. So, the mechanical power input to the DFIG is also decreased as shown in the graph. During this time, the additional power will come from the inertial response in the form of $\mathrm{KE}(\Delta P)$. Fig. 23 shows the terminal voltage response of VSWT-DFIG based WF. As it has the LVRT capability, so the terminal voltage is returned to the pre-fault value after the fault has been cleared for both cases. Finally, the output of proposed FLC (B) is plotted against wind speed in Fig. 24. It is seen that the controller provides variable gain depending upon the wind speed condition which validates the effectiveness of FLC.

Based on these simulation results, it is clear that VSWT-DFIG with proposed VIC during rated wind speed condition can avoid conventional SGs from becoming out of step after the generation outage of FSWT-SCIG based WF and PV power plant.

\subsection{Simulation Results for Below Rated Wind Speed} Condition Applied to DFIG This section investigates the power system dynamic performances for Case B, when the applied wind speeds to DFIG are lower than the rated condition $(11.5 \mathrm{~m} / \mathrm{s}$, $11.0 \mathrm{~m} / \mathrm{s}, 10.5 \mathrm{~m} / \mathrm{s}$ and $10 \mathrm{~m} / \mathrm{s})$. The objective of this analysis is to find the limit of minimum wind speed that the proposed VIC controlled DFIG can stabilize the power system effectively. Figs. 25 to 26 shows the active power output of VSWT-DFIG and frequency response of the hybrid power system, respectively, where wind speed applied to VSWT-DFIG is $11.5 \mathrm{~m} / \mathrm{s}$. It is clearly seen from Fig. 26 that the whole power system is stable. This is because the VSWT-DFIG is supplying effective amount of KE during transient period as shown in Fig. 25.

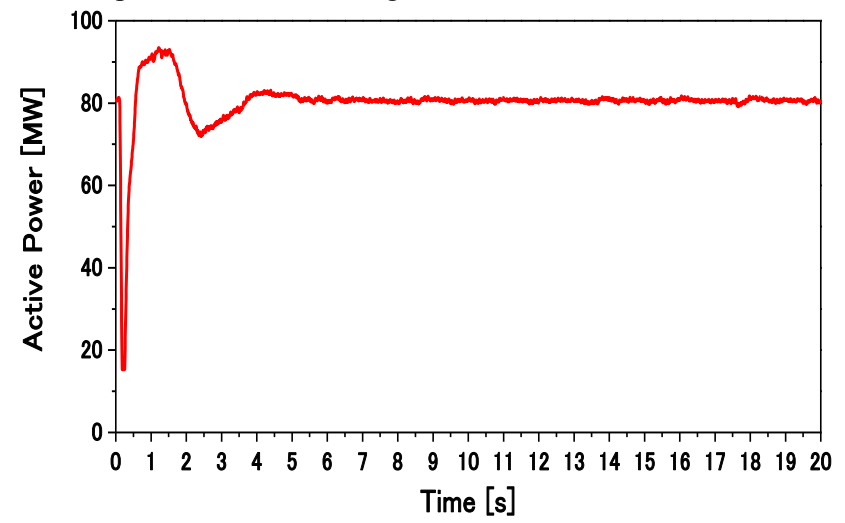

Fig. 25. Active power output of VSWT-DFIG $(11.5 \mathrm{~m} / \mathrm{s})$.

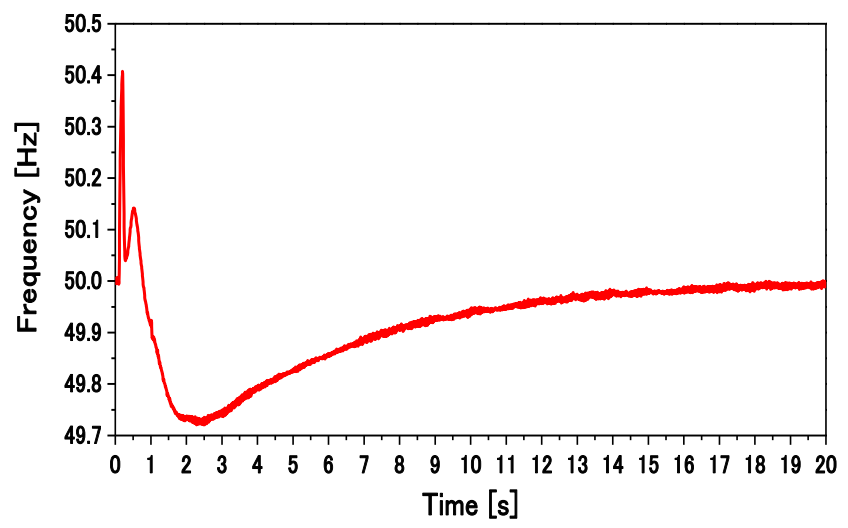

Fig. 26. Frequency response of the hybrid power system $(11.5 \mathrm{~m} / \mathrm{s})$

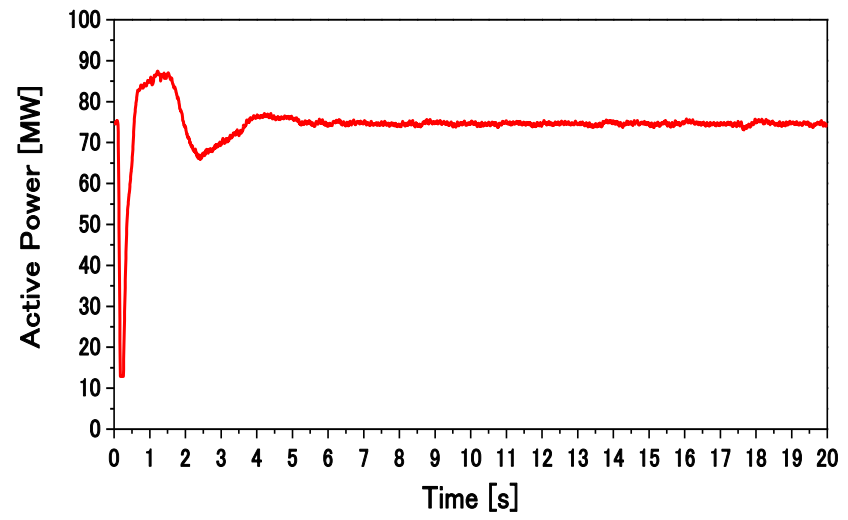

Fig. 27. Active power output of VSWT-DFIG $(11.0 \mathrm{~m} / \mathrm{s})$.

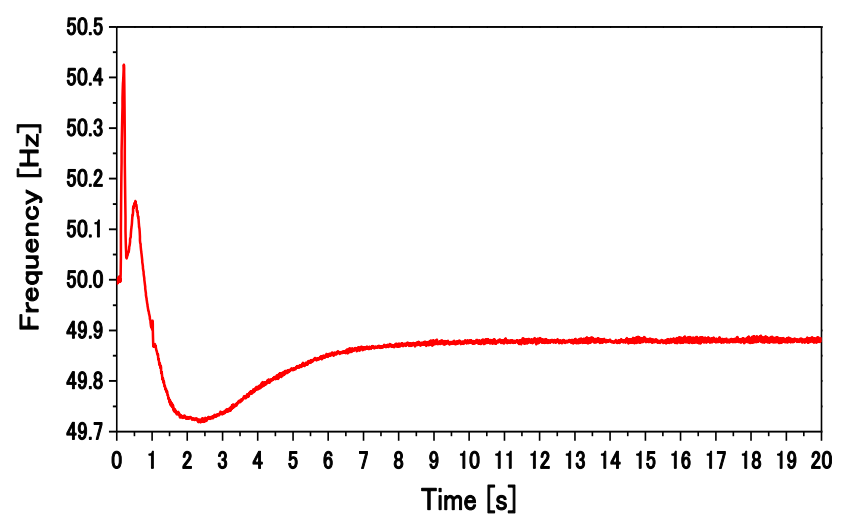

Fig. 28. Frequency response of the hybrid power system $(11.0 \mathrm{~m} / \mathrm{s})$.

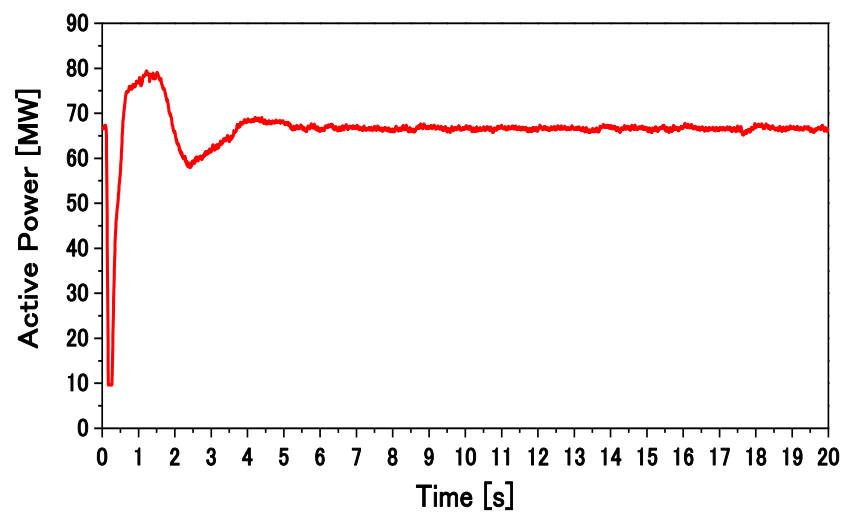

Fig. 29. Active power output of VSWT-DFIG $(10.5 \mathrm{~m} / \mathrm{s})$. 


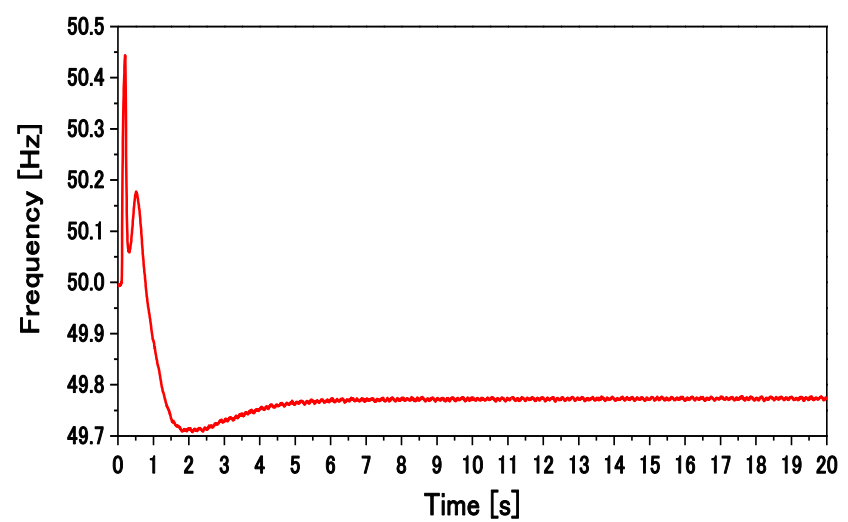

Fig. 30. Frequency response of the hybrid power system $(10.5 \mathrm{~m} / \mathrm{s})$.

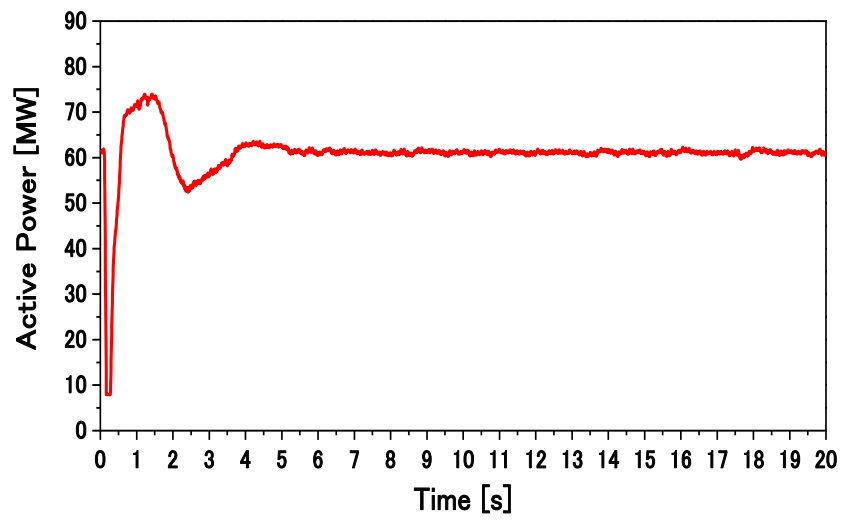

Fig. 31. Active power output of VSWT-DFIG $(10.0 \mathrm{~m} / \mathrm{s})$.

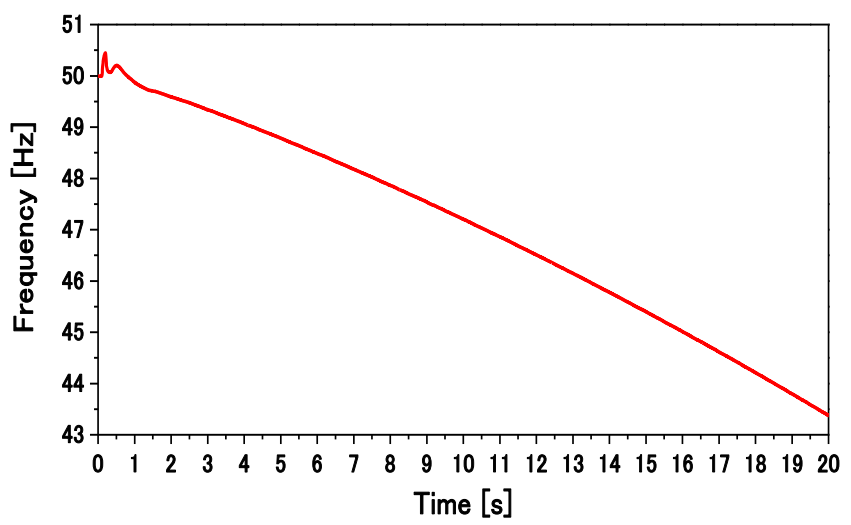

Fig. 32. Frequency response of the hybrid power system $(10.0 \mathrm{~m} / \mathrm{s})$.

Fig. 27 shows the active power output of VSWT-DFIG, where wind speed applied to VSWT-DFIG is $11.0 \mathrm{~m} / \mathrm{s}$. For this situation, the frequency of the hybrid power system is stable after the fault as illustrated in Fig. 28. Also, the frequency of the hybrid power system is stable, where the applied wind speed to VSWT-DFIG is $10.5 \mathrm{~m} / \mathrm{s}$ as shown in Fig. 30 .

Finally, Fig. 31 depicts the active power output of VSWT-DFIG, where the applied wind speed is $10.0 \mathrm{~m} / \mathrm{s}$. In this situation, the frequency of hybrid power system is declining after the fault and become unstable as illustrated in Fig. 32. This is because the active power output of VSWT-DFIG during steady state period and KE output during transient period are not sufficient to stabilize the power system. Even though the power system cannot be stabilized when the wind speed is low $(10.0 \mathrm{~m} / \mathrm{s})$ but the proposed VIC controlled VSWT-DFIG system can supply some amount of KE during the transient condition as shown in Fig. 31.

From the simulation results, though there is the lowest wind speed limit, the proposed VIC controlled DFIG can stabilize the power system if the wind speed is greater than the limit. It may be considered that the wind speed limit is dependent on the system configuration and conditions. Further investigations of the characteristics of the wind speed limit and control method when the wind speed is less than the limit are very important, and the authors intend to investigate the problems shortly.

\section{Conclusion}

To enhance the transient stability of a hybrid power system, a novel FLC based VIC is proposed in this paper. The proposed FLC controlled VIC can provide variable gain depending upon incoming wind speed. Different case studies are performed in PSCAD/EMTDC software. From the simulation analysis and discussions, the below points can be concluded.

(1) The proposed VIC controlled DFIG can supply additional amount of active power during transient period by releasing its stored $\mathrm{KE}$ in the rotor.

(2) The proposed VIC controlled DFIG can stabilize the power system after the generation outage if the wind speed is greater than the lowest limit.

Therefore, this proposed control strategy has a promising potential value for supporting the power system during generation outage. As a future work, investigations of the characteristics of wind speed limit and control method when the wind speed is less than the limit will be under consideration shortly, and the proposed VIC can be implemented through hardware prototype to verify the experimental results with theoretical results obtained in this paper. Also, the proposed VIC can be applied to VSWT-permanent magnet synchronous generator (PMSG) to stabilize the power system instead of VSWT-DFIG.

\section{Acknowledgement}

This study was supported by the Grant-in-Aid for Scientific Research (B) from The Ministry of Education, Science, Sports and Culture of Japan.

\section{Appendix}

\section{A1. Modeling of PV Power Plant}

A1.1 Design of PV Module The equivalent circuitry of a PV module is depicted Fig. A1. In this work, single diode model is used, which is simple but accurate ${ }^{(30)}$. The single diode model can be represented by current source, diode, and parallel and series resistances.

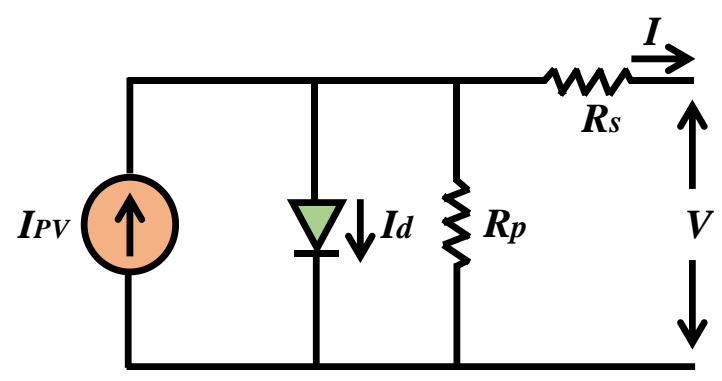

Fig. A1. Equivalent circuit of a single diode PV model. 
In this study, parameters of Kyocera KC200GT solar module are used to model the PV module ${ }^{(31)}$.

The aggregated model of a PV plant which is composed of a number of PV modules can be described as follows ${ }^{(30)-(33)}$ :

$$
I=N_{P} I_{P V}-N_{P} I_{o}\left[\exp \left(\frac{\left(V+R_{s}\left(\frac{N_{M}}{N_{P}}\right) I\right.}{N_{M} a V_{t}}\right)-1\right]-\frac{V+R_{s}\left(\frac{N_{M}}{N_{P}}\right) I}{R_{p}\left(\frac{N_{M}}{N_{P}}\right)}
$$

Here, $N_{M}$ is the number of series connected module in a string, $N_{P}$ is the number of parallel connected strings, $I_{P V}$ is the photovoltaic current, $I_{o}$ is the diode reverse saturation current, $R_{S}$ is the series resistance, $R_{p}$ is the parallel resistance, $a$ is the diode identity factor, $V_{t}=\left(N_{s} k T\right) / q$ is the module thermal voltage, $k$ is the Boltzmann constant $(1.3806503 \times 10-23 \mathrm{~J} / \mathrm{K}), T$ is the module temperature in Kelvin, and $q$ is the electron charge (1.60217646 X 10-19 C).

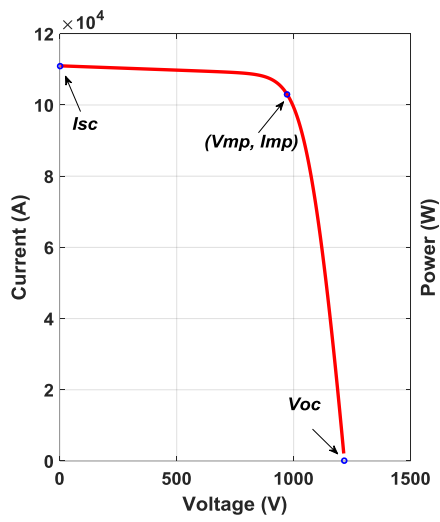

(a) $I$ vs $V$

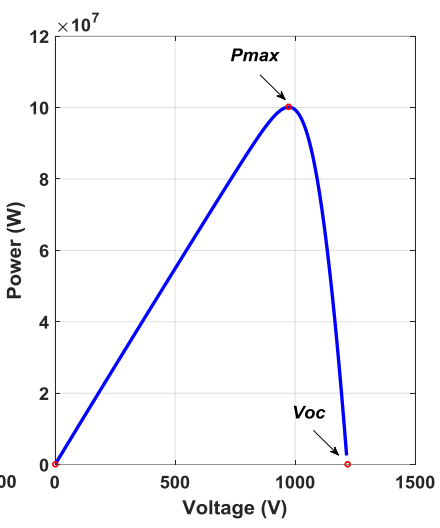

(b) $P$ vs $V$
Fig. A2. Characteristics curve of a $100 \mathrm{MW}$ PV power plant.

Table A1. Parameters of a 100 MW PV power plant.

\begin{tabular}{|c|c|}
\hline$P_{\max }$ & $100 \mathrm{MW}$ \\
\hline$V_{m p}$ & $973.1 \mathrm{~V}$ \\
\hline$I_{m p}$ & $102900 \mathrm{~A}$ \\
\hline$N_{m}$ & 37 \\
\hline$N_{p}$ & 13520 \\
\hline
\end{tabular}

The $I$ vs $V$ and $P$ vs $V$ characteristics curves for $100 \mathrm{MW} \mathrm{PV} \mathrm{unit}$ are illustrated in Fig. A2. Table A1 depicts the data for $100 \mathrm{MW}$ PV power plant.

\section{A1.2 Control Strategy of PV Power Plant}

A configuration of PV plant along with its control system is shown in Fig. A3. The overall system consists of a PV panel, DC/DC boost converter, and DC/AC inverter. The converter and inverter are controlled by boost converter controller and grid side inverter controller, respectively. The converter and inverter are based on IGBT. The PWM technique is used in this study for both converters. The DC line is modeled as stated in Ref. ${ }^{(34)}$ and the TOP SOLAR XZ-K (AS) $1 \times 300 \mathrm{~mm}^{2}$ cable parameters are used in this study ${ }^{(35)}$.

To boost up the output voltage level and extract the maximum power from the PV panel, a DC/DC boost converter is used in the $\mathrm{PV}$ plant. This is achieved by regulating the output voltage of the PV panel according to ambient temperature and irradiation. In this study, fractional open circuit voltage technique is used to extract maximum power. The boost converter controller is depicted in Fig. A4. Where, $V_{0}$ is the output voltage of the boost converter, $V$ is the actual output voltage of the PV panel, and $D$ is the duty cycle ${ }^{(31)}$.

During the grid fault situation, the $V_{d c}$ becomes very high because the incoming DC power from the PV panel cannot be injected to the grid due to severe voltage dip. So, an additional control scheme is implemented in the DC/DC boost converter controller where the MPPT controller is bypassed and PI based controller comes into the action. Due to this additional control strategies, the $V_{d c}$ lies within acceptable limit.

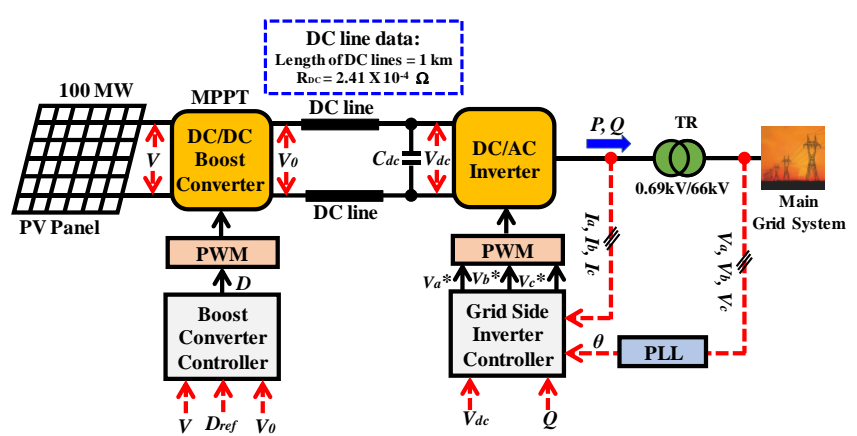

Fig. A3. Control scheme of PV plant.

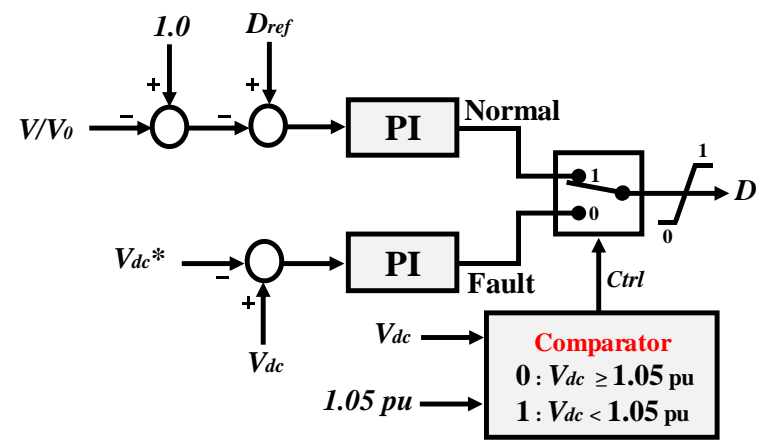

Fig. A4. DC/DC boost converter controller.

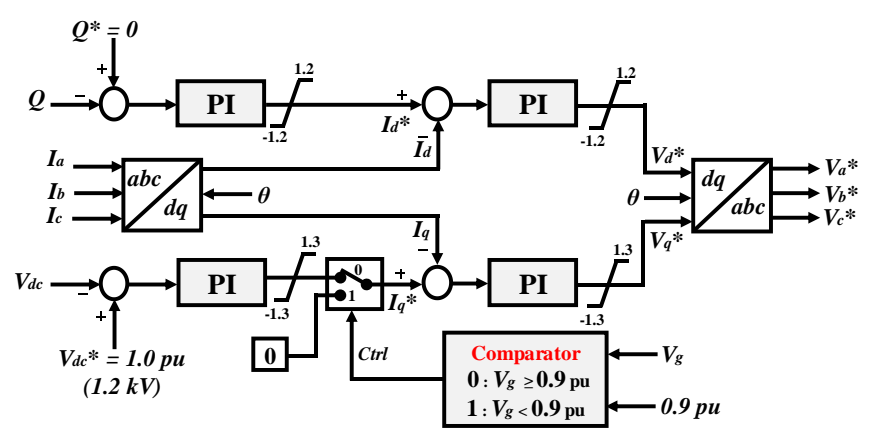

Fig. A5. Grid side inverter controller.

The DC/AC inverter converts the DC voltage into the three phase $\mathrm{AC}$ voltage of the grid frequency. The controller for the inverter is depicted in Fig. A5. It consists of four conventional PI controllers. The grid side inverter controller is used to control the reactive power delivered to the grid and keep the $V_{d c}$ constant. The reactive power reference is set to $0.0 \mathrm{pu}$ for unity PF operation. In normal operating condition $\left(V_{g}>0.9 \mathrm{pu}\right)$, the grid side inverter regulates the active power delivered to the grid. During a fault condition $\left(V_{g}\right.$ $<0.9 \mathrm{pu}$ ), the comparator sends signal so that active power transfer to the grid becomes zero. 


\section{References}

(1) The Global Wind Energy Council (GWEC) (2016). [Online]. Available: http://gwec.net/publications/global-wind-report-2/global-wind-report-2016/.

(2) M. A. G. de Brito, L. P. Sampaio, G. Luigi, G. A. e Melo and C. A. Canesin, "Comparative analysis of MPPT techniques for PV applications," Proc. Int. Conf. Clean Elect. Power (ICCEP), pp. 99-104 (2011).

(3) H. Bevrani, A. Ghosh and G. Ledwich, "Renewable energy sources and frequency regulation: survey and new perspectives", IET Renewable Power Generation, Vol.4, No. 5, pp.438-457 (2010-9)

(4) K. Dehghanpour, S. Afsharnia, "Electrical demand side contribution to frequency control in power systems: a review on technical aspects", Ren. and Sustain. Energy Reviews, Vol.41, pp.1267-1276 (2015)

(5) J. Ekanayake and N. Jenkins, "Comparison of the response of doubly fed and fixed-speed induction generator wind turbines to changes in network frequency", IEEE Trans. Energy Convers., Vol.19, No.4, pp.800-802 (200412)

(6) G. Lalor, A. Mullane, and M. O'Malley, "Frequency control and wind turbine technologies", IEEE Trans. Power Syst., Vol.20, No.4, pp.1905-1913 (200511)

(7) M. Kayikci and J. V. Milanovic, "Dynamic contribution of DFIG based wind plants to system frequency disturbances", IEEE Trans. Power Syst., Vol.24, No.2, pp.859-867 (2009-5)

(8) J. Morren, J. Pierik, and S. W. H. de Haan, "Inertial response of variable speed wind turbines", Elect. Power Syst. Res., Vol.76, No.11, pp.980-987 (2006-7)

(9) J. Morren, S. Haan, W. L. Kling, and J. A. Ferreira, "Wind turbines emulating inertia and supporting primary frequency control", IEEE Trans. Power Syst., Vol.21, No.1, pp.433-434 (2006-2)

(10) G. Ramtharan, J. B. Ekanayake, and N. Jenkins, "Frequency support from doubly fed induction generator wind turbines", IET Renew. Power Gener., Vol.1, No.1, pp.3-9 (2007-3)

(11) I. D. Margaris, S. A. Papathanassiou, N. D. Hatziargyriou, A. D. Hansen, and P. Sørensen, "Frequency control in autonomous power systems with high wind power penetration", IEEE Trans. Sustain. Energy, Vol.3, No.2, pp.189$199(2012-4)$

(12) J. F. Conroy and R. Watson, "Frequency response capability of full converter wind turbine generators in comparison to conventional generation", IEEE Trans. Power Syst., Vol.23, No.2, pp.649-656 (2008-5)

(13) J. V. D. Vyver, J. D. M. D. Kooning, B. Meersman, L. Vandevelde, and T. L. Vandoorn, "Droop control as an alternative inertial response strategy for the synthetic inertia on wind turbines", IEEE Trans. Power Syst., Vol.31, No.2, pp.1129-1138 (2016-3)

(14) T. Ackerman: Wind power in power system, UK: John Wiley \& Sons (2005)

(15) WECC renewable energy modeling task force, WECC Wind Power Plant Dynamic Modeling Guide (2014-4)

(16) S. M. Muyeen, J. Tamura and T. Murata: Stability augmentation of a grid connected wind firm, London, Springer-Verlag (2009)

(17) Matlab documentation center [online]. Availbale: http://www.mathworks. co.jp/jp/help/. Matlab documentation Center (Last accessed: 01 November 2017).

(18) M. Rosyadi, A. Umemura, R. Takahashi, J. Tamura, N. Uchiyama and K. Ide, "Simplified model of variable speed wind turbine generator for dynamic simulation analysis", IEEJ Trans. on Power and Energy, Vol.135, No.9, pp.538-549 (2015)

(19) J. Liu, M. Rosyadi, A. Umemura, and R. Takahashi, J. Tamura, "A control method of permanent magnet wind generators in grid connected wind farm to damp load frequency oscillation", IEEJ Trans. on Power and Energy, Vol. 134 No.5, pp.393-398 (2014)

(20) N. W. Miller, W. W. Pric and J. J. Samches-Gasca, "Dynamic modeling of GE 1.5 and 3.6 wind turbines-generators", GE-Power System Energy Consulting (2003)

(21) PSCAD/EMTDC user`s manual. Manitoba HVDC Research Center, Canada (1994)

(22) M. Stiebler: Wind energy systems for electric power generation, New York, USA, Springer (2008)

(23) J. Morren, J. Pierik, and S. W. de Haan, "Inertial response of variable speed wind turbines," Elect. Power Syst. Res., Vol.76, pp.980-987 (2006)

(24) J. M. Mauricio, A. Marano, A. Gomez-Exposito, and J. L. M. Ramos, "Frequency regulation contribution through variable-speed wind energy conversion systems", IEEE Trans. Power Syst., Vol. 24, No.1, pp.173-180 (2009-2)

(25) L. Holdsworth, J. Ekanayake, N. Jenkins, "Power system frequency response from fixed speed and doubly fed induction generator based wind turbines", Wind Energy, Vol. 7, pp. 21-35 (2004)

(26) P. K. Keung, P. Li, H. Banakar, B. T. Ooi, "Kinetic energy of wind turbine generators for system frequency support”, IEEE Trans. Power Syst., Vol. 24,
No. 1, pp. 279- 287 (2009)

(27) D. Driankov, H. Hellendoorn, and M. Reinfrank: An Introduction to Fuzzy Control. Berlin, Germany, Springer-Verlag (1993)

(28) Sugeno, M.: Industrial applications of fuzzy control, Elsevier Science Pub. Co. (1985)

(29) B. K. Bose, Modern power electronics and AC drives, Prentice Hall, PTR.

(30) M. Hasanien, "An Adaptive Control Strategy for Low Voltage Ride Through Capability Enhancement of Grid-Connected Photovoltaic Power Plants", IEEE Trans. on Power Sys., Vol.31, No.4, pp.3230-3237 (2016-7)

(31) Kyocera KC200GT- high efficiency multi crystal photovoltaic module datasheet.

(32) G. M. S. Islam, A. Al-Durra, S. M. Muyeen and J. Tamura, "A robust control scheme to enhance the stability of a grid-connected large scale photovoltaic system", PES T\&D 2012, Orlando, FL, pp.1-6 (2012)

(33) M. K. Hossain and M. H. Ali, "Low voltage ride through capability enhancement of grid connected PV system by SDBR," Proc. in IEEE PES T\&D Conf. Expo., pp.1-5 (2014)

(34) M. R. Starke, "DC distribution with fuel cells as distributed energy resources", Ph.D. dissertation, Dept. Electric. Eng., Univ. Tennessee, Knoxville (2009)

(35) Cables for photovoltaic solar installations. [Online]. Available: www.elesis.gr/php/download.php?file=solar_cables_presentation.pdf

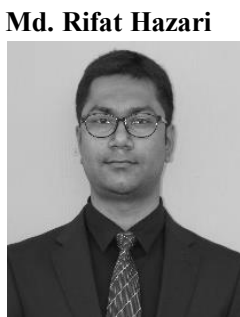

(Student Member) received his B.Sc Engg. and M.Sc. Engg. Degrees in Electrical and Electronic Engineering from American International University-Bangladesh (AIUB) in August 2013 and December 2014, respectively. Then he joined as a lecturer in Electrical and Electronic Engineering department at AIUB. Currently, he is working towards his $\mathrm{Ph} . \mathrm{D}$. degree at Kitami Institute of Technology (KIT), Japan. He has received a best paper award from the international conference, AUPEC2017, in 2017. His research interests are renewable energy systems (especially wind power \& photovoltaic power systems), power system stability and control, microgrid and hybrid power systems, HVDC system, analysis and control of rotating electrical machines. $\mathrm{He}$ is the student member of IEEE Power and Energy Society and IEEJ.

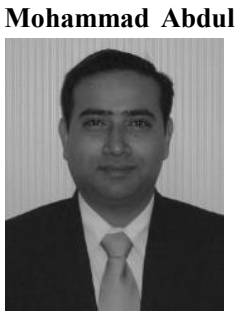

Mannan (Non Member) was born in Laxmipur, Bangladesh on January 01, 1975. He received his B. Sc. Eng. Degree from Rajshahi University of Engineering and Technology (RUET former BITR), Bangladesh, in 1998, and Masters of Eng. and Dr. of Eng. degrees from Kitami Institute of Technology, Japan, in 2003 and 2006 respectively, all in electrical engineering. He then joined in the American International University Bangladesh (AIUB) as an Assistant professor on May 2006. He served in AIUB as an Associate Professor from December 2013 to November 2016. Now he is working as a Professor and Head of undergraduate program in AIUB. His research interests include electric motor drive, power electronics, power system, wind generation system and control of electric motor, power electronic converters, power system, and wind generation system. Prof. Dr. Mannan is a member of the IEB and IEEE.

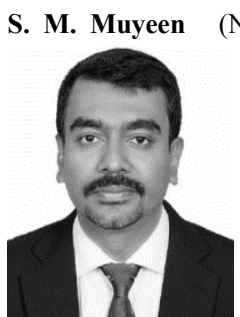

Non Member) received his B.Sc. Eng. Degree from Rajshahi University of Engineering and Technology (RUET), Bangladesh formerly known as Rajshahi Institute of Technology, in 2000 and M. Eng. and Ph.D. Degrees from Kitami Institute of Technology, Japan, in 2005 and 2008, respectively, all in Electrical and Electronic Engineering. At the present, he is working as an Associate Professor in the Department of Electrical and Computer Engineering at Curtin University, Perth, Australia. His research interests are power system stability and control, electrical machine, FACTS, energy storage system (ESS), 
Renewable Energy, and HVDC system. He has been a Keynote Speaker and an Invited Speaker at many international conferences, workshops, and universities. He has published over 150 articles in different journals and international conferences. He has published five books as an author or editor. $\mathrm{He}$ is serving as Editor/Associate Editor for many prestigious Journals from IEEE, IET, and other publishers including IEEE Transactions of Sustainable Energy, IEEE Power Engineering Letters, IET Renewable Power Generation and IET Generation, Transmission \& Distribution, etc. Dr. Muyeen is the senior member of IEEE and Fellow of Engineers Australia.

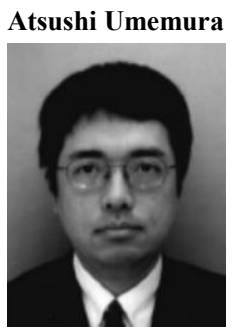

(Member) received Dr. Eng. degree from Tokyo Denki University and joined Ohashi Engineering Co. Ltd. He became an Assistant Professor in the Electrical and Electronic Engineering, Kitami Institute of Technology since 2012. His research interests include robotics, mechatronics and power electronics.

\section{Rion Takahashi}

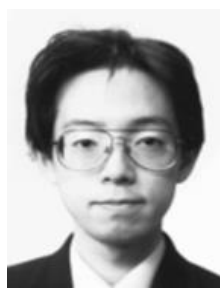

(Member) received the B.Sc. Eng. and Dr. Eng. Degrees from Kitami Institute of Technology, Japan, in 1998 and 2006 respectively, all in Electrical and Electronic Engineering. Now he is working as Associate Professor in Department of Electrical and Electronic Engineering, Kitami Institute of Technology. His major research interests include analysis of power system transient, FACTS and wind energy conversion system. He is a member of IEEE.

Junji Tamura

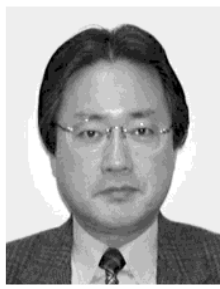

(Member) received his B. Sc. Eng. Degree from Muroran Institute of Technology, Japan, in 1979 and M.Sc. Eng. and Dr. Eng. degrees from Hokkaido University, Japan, in 1981 and 1984 respectively, all in electrical engineering. He became a lecturer in 1984, an Associate Professor in 1986, and a Professor in 1996 at the Kitami Institute of Technology, Japan. Currently he is an Executive Vice President of the Kitami Institute of Technology. Prof. Dr. Tamura is a Senior Member of the IEEE Power Engineering Society. 